\title{
Monthly Mean Solar Radiative Fluxes and Cloud Forcing over South America in the Period of 1986-88: GCM Results and Satellite-Derived Data
}

\author{
Tatiana A. Tarasova and Iracema F. A. Cavalcanti \\ Centro de Previsão de Tempo e Estudos Climáticos/Instituto Nacional de Pesquisas Espaciais, Cachoeira Paulista, Brazil
}

(Manuscript received 2 April 2001, in final form 11 February 2002)

\begin{abstract}
The incident solar radiative fluxes, simulated by an atmospheric general circulation model over South America for the period 1986-88, are compared with the satellite-derived surface fluxes provided by the Surface Radiation Budget (SRB) datasets. The comparison shows that the model systematically overestimates both all-sky and clear-sky SRB fluxes while representing well their latitudinal variations. In order to analyze the reasons for the bias, the shortwave radiation code employed in the model is tested with more comprehensive techniques in a stand-alone mode. The results of testing demonstrate that the code underestimates solar radiation absorption in the clear-sky atmosphere due to trace gases and aerosols. The underestimation of the absorption due to aerosols contributes noticeably to the surface flux bias. The impact of clouds on the surface fluxes is estimated by calculating cloud radiative forcing, defined as the difference between the net surface fluxes in all-sky and clearsky conditions. The comparison of model-simulated and satellite-derived values of cloud radiative forcing over South America demonstrates that the model simulates fairly well its latitudinal variations and annual cycles as compared with SRB data. However, the model overestimates the SRB surface cloud radiative forcing over the tropical region of South America and underestimates it over the extratropical region in both January and July. The comparisons of the incident surface fluxes simulated by the model at the grid points with those measured at three Amazonian observational sites show good agreement at one site and large discrepancies at the other two sites.
\end{abstract}

\section{Introduction}

The distribution of solar radiation in the earth's climate system strongly influences its thermal and dynamical conditions. Hence, an accurate simulation of solar radiative fluxes incoming at the surface and at the top of the atmosphere is a prerequisite for the good performance of general circulation models (GCMs). For example, excess of solar radiation at the earth's surface can lead to unrealistically high surface temperatures and to an atmospheric hydrological cycle inconsistent with observations.

The comparison of surface solar radiative fluxes simulated by the GCM of the Max Planck Institute for Meteorology, Hamburg, Germany, with those instrumentally measured demonstrates that the model overestimates measured fluxes by $45 \mathrm{~W} \mathrm{~m}^{-2}$ over most of the European sites in summer (Wild et al. 1995). The measured fluxes used for the comparison were obtained from the Global Energy Balance Archive (GEBA; Gilgen et al. 1998). Further studies have shown that most atmospheric GCMs overestimate measured surface solar

Corresponding author address: Dr. Tatiana Tarasova, CPTEC/ INPE, Rodovia Presidente Dutra, km. 40, 12630-000, Cachoeira Paulista, SP, Brazil.

E-mail: tatiana@cptec.inpe.br fluxes because of the underestimation of atmospheric absorption (Cess et al. 1995). The analysis of the bias between the values of the solar radiation absorption in the atmosphere, simulated by four European GCMs and provided by 720 GEBA European sites in conjunction with satellite measurements, indicates that the modelsimulated absorption is $10-20 \mathrm{~W} \mathrm{~m}^{-2}$ smaller than that obtained from observations (Wild and Ohmura 1999). More than one-half of this value is due to the underestimation of the absorption in a cloud-free atmosphere. The bias increases to $20-40 \mathrm{~W} \mathrm{~m}^{-2}$ in the low latitudes and to $30 \mathrm{~W} \mathrm{~m}^{-2}$ over areas of equatorial Africa with high aerosol loadings (Wild 1999). The reason for the lack of atmospheric absorption in the models is assumed to be the underestimation of the absorption due to water vapor and aerosols (Wild and Ohmura 1999). The errors of solar radiation measurements can also be partially responsible for the discrepancies (Gilgen et al. 1998).

Large flux bias in low latitudes highlights the need for an investigation of the model-simulated incident solar fluxes in the Tropics. The overestimation of the surface solar radiative fluxes over South America by an atmospheric GCM as compared with satellite-derived data was demonstrated in Tarasova and Cavalcanti (2000). For the flux simulation, the CPTEC-COLA GCM was used. This GCM was developed at the Center 
for Ocean, Land, and Atmosphere Studies (COLA) and is currently utilized for weather and seasonal climate forecast at the Brazilian center for weather prediction and climate studies (CPTEC). The model is also used for many research applications at COLA, CPTEC, and some other centers. The modeled fluxes were compared with the satellite-derived fluxes provided by the Surface Radiative Budget (SRB) project datasets (Whitlock et al. 1993).

In this study, we analyze more closely the capability of the CPTEC-COLA model to simulate space and time variations of SRB surface solar radiative fluxes and shortwave cloud radiative forcing over South America. The similar space resolution of the satellite-derived and model-simulated surface fluxes allows detailed comparisons. The scarcity of ground-based pyranometer measurements over South America is another reason to use the SRB datasets. Despite the errors related to approximate methods of surface flux derivation from satellite data, strong correlation between the upward flux at the top of the earth's atmosphere and downward flux at the surface allows the surface fluxes to be derived with fairly good accuracy ( $\mathrm{Li}$ et al. 1993).

The description of the CPTEC-COLA model integrated over $11 \mathrm{yr}$ is given in section 2 . Section 3 briefly describes the SRB datasets. Section 4 presents a comparison of the modeled surface fluxes and SRB data in all-sky and cloudfree conditions as well as variations of the cloud radiative forcing with latitude and longitude, its annual cycle, and interannual variability. The stand-alone validation of the shortwave radiation code used in the CPTEC-COLA GCM with more comprehensive techniques is given in section 5. Section 6 describes ground-based measurements of all-sky-clear-sky atmospheric transmission ratio in Amazonia at three observational sites and its comparison with collocated data provided by the model-simulated and satellite-derived datasets. The results and conclusions are given in section 7 .

\section{Integration of the CPTEC-COLA GCM for $11 \mathrm{yr}$}

The original COLA model was derived from the National Centers for Environmental Prediction (NCEP) GCM. COLA introduced several processes, mainly related to the interaction of land and atmosphere, such as the vegetation module Simple Surface Biosphere Model (SSIB; Xue et al. 1991). The COLA version also presents modifications on radiation, cloud-radiation interactions, and treatment of vertical diffusion (Sato et al. 1989; Hou 1990). The convection scheme used in this study is the Kuo scheme (Kuo 1974). The dynamical and physical processes are described in Kinter et al. (1997).

The shortwave radiative fluxes in the model are simulated with the use of the broadband radiation code following the parameterizations of Lacis and Hansen (1974). The code takes into account Rayleigh scattering, absorption due to water vapor and ozone, as well as scattering and absorption by cloud particles. The absorption due to water vapor is computed with the broadband absorption function of Yamamoto (1962). The radiative transfer in an atmosphere with clouds is solved with two-stream and adding-doubling approaches. The cloud cover scheme utilizes the parameterizations of Slingo (1987), which allow for the four cloud types: convective (cumulus, cumulonimbus), high (cirrus), middle (altostratus, altocumulus), and low (stratus, stratocumulus). The cloud cover of the convective clouds linearly depends on the time-averaged precipitation rate at the cloud base provided by the convection scheme. The cloud cover of the high-, mid-, and low-level clouds depends mainly on the relative humidity at the cloud level.

The main changes introduced by CPTEC in the COLA GCM were related to the kind of truncation (from rhomboidal to triangular), dissipation process, computational time performance, postprocessing scheme, and increase of the vertical levels. More details on these modifications can be found in Cavalcanti et al. (2001). The model results used in the present study were obtained from a climatological simulation using the CPTEC-COLA GCM with the resolution T42L18 (triangular truncation of 42 waves in the horizontal coordinate and 18 vertical levels). The integration was performed with one initial condition (NCEP data of 15 September 1985) for a period from September 1986 to December 1996. Monthly observed sea surface temperature (SST) data (Reynolds and Smith 1994) were applied as a forcing boundary condition. Other boundary conditions, such as soil humidity and surface temperature, were introduced as initial climatological conditions adjusted during the integration. Albedo is predicted by the SSIB over the land and is a function of solar zenith angle over the ocean. The output of the model integration results is given at the regular space grid of $2.5^{\circ} \times 2.5^{\circ}$.

\section{Surface Radiative Budget project data}

The surface solar radiative fluxes in the SRB datasets (1985-88) have been generated from the satellite data by using two different radiative transfer algorithms (Whitlock et al. 1993). The 3-h parameters, such as radiance, cloud amount, precipitable water, and ozone amount, all provided by the International Satellite Cloud Climatology Project (ISCCP; Rossow et al. 1991), were utilized as inputs to the algorithms. Both methods apply spectral and angular corrections based on Nimbus-7 Earth Radiation Budget (ERB) and Earth Radiation Budget Experiment (ERBE) results (Suttles et al. 1992).

The SRB clear-sky and all-sky surface fluxes are available for the period from March 1985 to December 1988 for 6596 cells $(280 \mathrm{~km} \times 280 \mathrm{~km})$ over the globe. In this study, we utilize the fluxes computed with the method of Pinker and Laszlo (1992, hereinafter PL), which is the physical radiative transfer algorithm based 
on the delta-Eddington approximation. The method accounts for the absorption by ozone, water vapor, and Rayleigh scattering, as well as multiple scattering and absorption by aerosols and clouds in five spectral intervals. The absorption by water vapor and ozone is computed following the parameterizations of Lacis and Hansen (1974). The amounts of gases are obtained from the daily average TOVS information. The standard aerosol profiles Mar-I and Cont-I (WCRP-112 1986) are incorporated over oceans and continents, respectively. Seasonal variation of the aerosol loading is not taken into account. This can lead to errors in the surface fluxes over areas with forest and savannah fires. The shortcomings of the ISCCP data themselves also influence the accuracy of surface flux derivation.

The validation of the SRB all-sky surface radiative fluxes has been performed using the observations at the 250 GEBA sites located in Europe, Canada, the Far East, and Fuji. The average biases between the satellite-derived and surface-measured monthly mean fluxes are small when estimated for 25 ISCCP cells each containing more than three GEBA sites. Thus for July 1985 the average bias is $+5 \mathrm{~W} \mathrm{~m}^{-2}$ with the root-mean-square error of $21 \mathrm{~W} \mathrm{~m}^{-2}$. The validation of the SRB clearsky fluxes has not been performed in that comparison. Further comprehensive testing of the PL algorithm with the ground-based measurements of the Solar and Infrared Observation System (SIROS) of the Atmospheric Radiation Measurements Program (ARM) for 487 time steps covering about one month showed that the calculated clear-sky diffuse solar fluxes are larger than those measured by $7 \mathrm{~W} \mathrm{~m}^{-2}$ (Laszlo and Pinker 2001). The estimated bias in the all-sky global fluxes is about $17 \mathrm{~W} \mathrm{~m}^{-2}$ when averaged for a month.

\section{Monthly mean shortwave radiative fluxes and cloud radiative forcing}

The monthly mean shortwave radiative fluxes, provided by the model-simulated and SRB datasets, were averaged over 3 yr (1986-88) and over the latitudinal zones of $2.5^{\circ}$ over South America excluding coastal areas. The variation of the mean fluxes with latitude is shown in Fig. 1 for January and July. One can see that the model-simulated and SRB fluxes demonstrate similar variations with latitude, related mainly to the change of solar zenith angle and cloudiness. Nevertheless, the modeled fluxes are systematically larger in both all-sky and clear-sky conditions. The difference between the model-simulated and SRB all-sky fluxes ranges from 0 to $100 \mathrm{~W} \mathrm{~m}^{-2}$ in January and from 0 to $30 \mathrm{~W} \mathrm{~m}^{-2}$ in July. The clear-sky flux bias varies from 20 to $40 \mathrm{~W}$ $\mathrm{m}^{-2}$ in January and from 10 to $40 \mathrm{~W} \mathrm{~m}^{-2}$ in July.

The main distinction of the SRB algorithm from the radiation code employed in the model is associated with the incorporation of the aerosol optical properties. Hence the bias between the model-simulated and SRB clear-sky fluxes is related in part to the aerosol impact
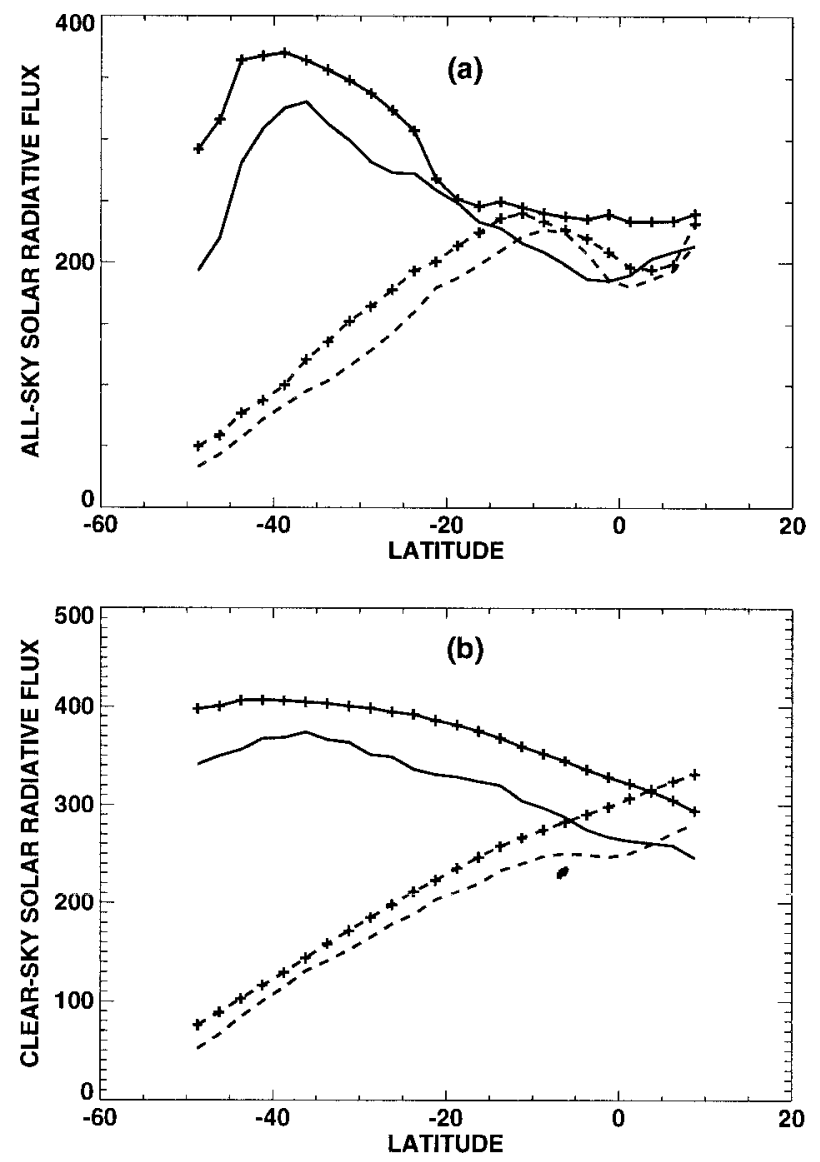

FIG. 1. Monthly mean (a) all-sky and (b) clear-sky solar radiative fluxes incoming at the surface in Jan (solid) and Jul (dashed). The fluxes are averaged over South America in each latitudinal zone of $2.5^{\circ}$ and over $3 \mathrm{yr}, 1986-88$. Pluses denote the model results; curves without marks show SRB data.

that is discussed in section 5. The difference between observed and modeled moisture fields used in the SRB and model radiation calculations also leads to the flux biases. Probably the effect is not strong because of the fast saturation of the water vapor absorption lines in the humid tropical and subtropical atmospheres. Both SRB and model radiation algorithms slightly underestimate the atmospheric absorption due to the trace gases.

In order to quantify the radiative effect of clouds, we calculated the magnitude of cloud radiative forcing $\left(\mathrm{CRF}_{s}\right)$ and all-sky-clear-sky atmospheric transmission ratio (ATR) using both model-simulated values and SRB data. By its definition, cloud radiative forcing at the surface is the difference between the net surface fluxes in the all-sky $\left(N_{s}\right)$ and clear-sky $\left(N_{s}^{c}\right)$ conditions: $\mathrm{CRF}_{s}$ $=N_{s}-N_{s}^{c}$. The cloud radiative forcing term has been proposed to study the influence of clouds on the atmospheric general circulation in GCMs (Ramanathan 1987). The value of $\mathrm{CRF}_{s}$ depends on cloud parameters as well as on the extraterrestrial solar flux and surface albedo. The atmospheric transmission ratio is defined as the ratio between the incident fluxes in the all-sky 

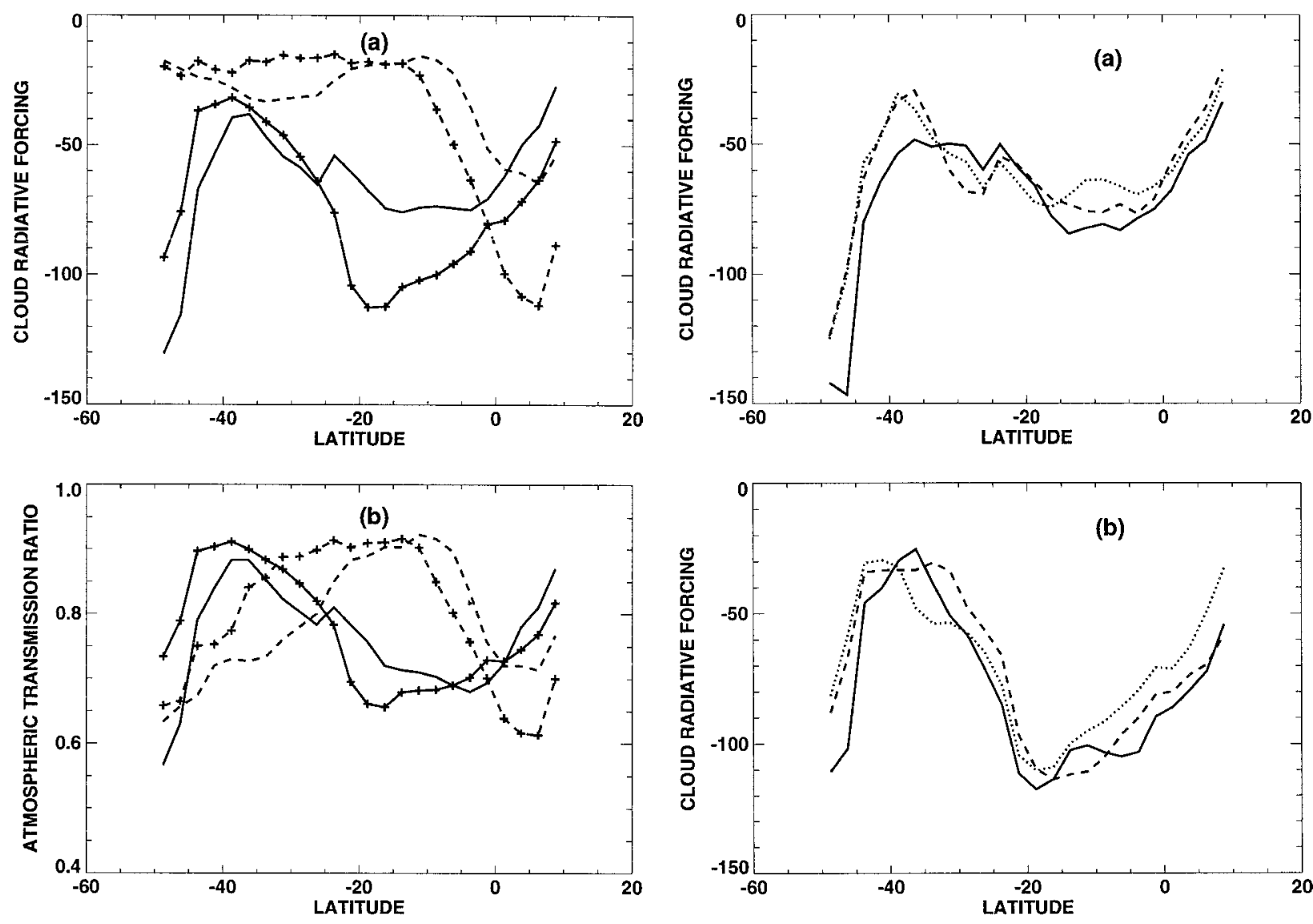

FIG. 2. As in Fig. 1 but for (a) cloud radiative forcing and (b) allsky-clear-sky atmospheric transmission ratio.

$\left(S_{i}\right)$ and clear-sky $\left(S_{i}^{c}\right)$ conditions: ATR $=S_{i} / S_{i}^{c}$. The magnitude of ATR depends mainly on cloud cover and cloud optical depth and can be accurately measured on the ground, providing additional verification for GCM and satellite data.

The variations of monthly mean cloud radiative forcing and all-sky-clear-sky atmospheric transmission ratio with latitude are shown in Fig. 2 for January and July (3-yr averages: 1986-88). Both the model-simulated and SRB datasets capture all the main features of the cloudiness impact on the incident solar flux in the different climate zones. Near the equator, the magnitude of the atmospheric transmission ratio is almost the same in January and July (about 0.7 ). In the tropical latitudes from $5^{\circ}$ to $22^{\circ} \mathrm{S}$, the ATR value varies from 0.8 to 0.9 in July, which is a dry season month with few clouds, and ranges from 0.7 to 0.8 in January due to the thick clouds of the wet period. In the extratropical latitudes, to the south of $22^{\circ} \mathrm{S}$, clouds appear more effective in reducing the incident shortwave flux in July than in January. Nevertheless, the cloud radiative forcing in these latitudes is smaller in July than in January due to the smaller extraterrestrial incident solar flux in July. Figure 2 also demonstrates that there are quantitative discrepancies between the modeled and SRB values of

FIG. 3. (a) SRB monthly mean cloud radiative forcing in Jan 1986 (solid), 1987 (dotted), and 1988 (dashed); (b) model-simulated data.

ATR, which leads to the large bias between the magnitudes of $\mathrm{CRF}_{s}$ in the tropical latitudes in January, for example. The interannual variations of monthly mean cloud radiative forcing for the period from 1986 to 1988 are shown in Figs. 3 and 4 for the model results and $\mathrm{SRB}$ data. The interannual variability of $\mathrm{CRF}_{s}$ in tropical latitudes is less than $20 \mathrm{~W} \mathrm{~m}^{-2}$ in January and $10 \mathrm{~W}$ $\mathrm{m}^{-2}$ in July in both datasets.

The annual cycle of monthly mean cloud radiative forcing and atmospheric transmission ratio zonally averaged over four South America latitudes and $3 \mathrm{yr}$ (1986-88) is presented in Figs. 5 and 6. One can see that the annual cycle of the atmospheric transmission ratio is weak at the latitudes of $31.25^{\circ}$ and $46.25^{\circ} \mathrm{S}$ in both model-simulated and SRB datasets, but there is a pronounced annual cycle of cloud radiative forcing at $46.25^{\circ} \mathrm{S}$ associated with strong seasonal variations of the extraterrestrial incident solar flux. At the tropical latitude of $16.25^{\circ} \mathrm{S}$, both $\mathrm{CRF}_{s}$ and ATR have pronounced annual cycles related to the change of cloud amount in the dry and wet seasons. In the equatorial region, the annual cycles of $\mathrm{CRF}_{s}$ and ATR are also weak. The bias between the model and SRB cloud radiative forcing values reaches $40 \mathrm{~W} \mathrm{~m}^{-2}$ at $16.25^{\circ} \mathrm{S}$ in January and at $1.25^{\circ} \mathrm{S}$ in August. 

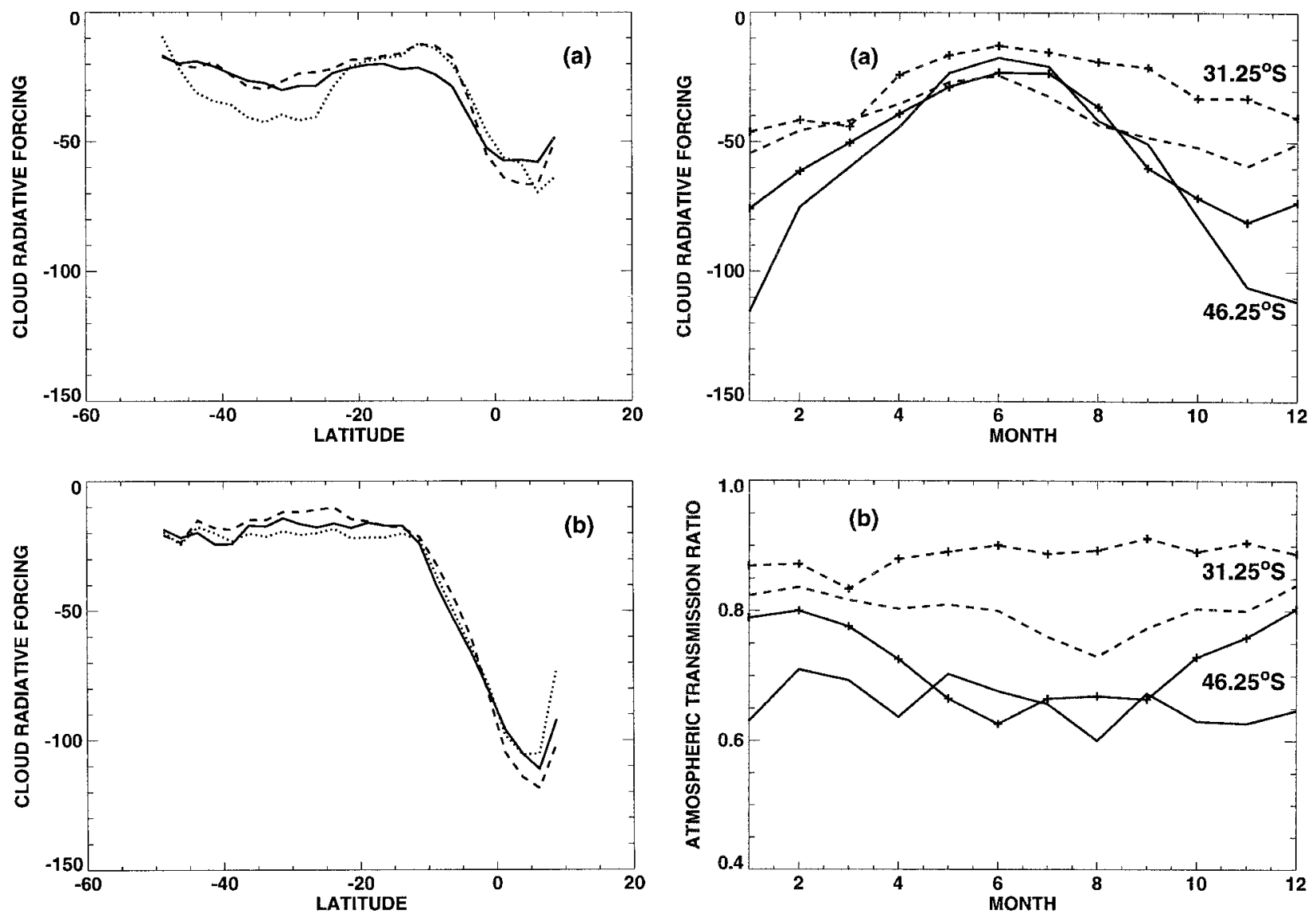

FIG. 4. As in Fig. 3 but for Jul.

\section{The stand-alone validation of the radiation code employed in the model}

To analyze the possible deficiencies of the shortwave radiation code employed in the CPTEC-COLA GCM, we performed calculations with the code in a standalone mode. The test cases used in the calculations have been proposed by the ICRCCM working group for the intercomparison of the radiative transfer algorithms (Fouquart and Bonnel 1991). The calculated incident surface flux and atmospheric absorption are compared with those computed by the benchmark line-by-line (LBL) method (Fomin and Gershanov 1996). The method accounts for the absorption lines of $\mathrm{H}_{2} \mathrm{O}, \mathrm{O}_{3}, \mathrm{O}_{2}$, and $\mathrm{CO}_{2}$, available in the HITRAN-96 database (Rothman et al. 1998), as well as for the water vapor continuum model of Clough et al. (1989). The GCM radiation code takes into account the absorption due to $\mathrm{H}_{2} \mathrm{O}$ and $\mathrm{O}_{3}$. The discrepancies between the results obtained with the code and LBL method are related to the different methods of the solution of the radiative transfer equation as well as to the different gases and aerosols incorporated. The conclusion that the latter effect is stronger was obtained on the basis of the sensitivity tests performed with the LBL method alone.

The test cases 31, 33, 35, and 37 shown in Table 1

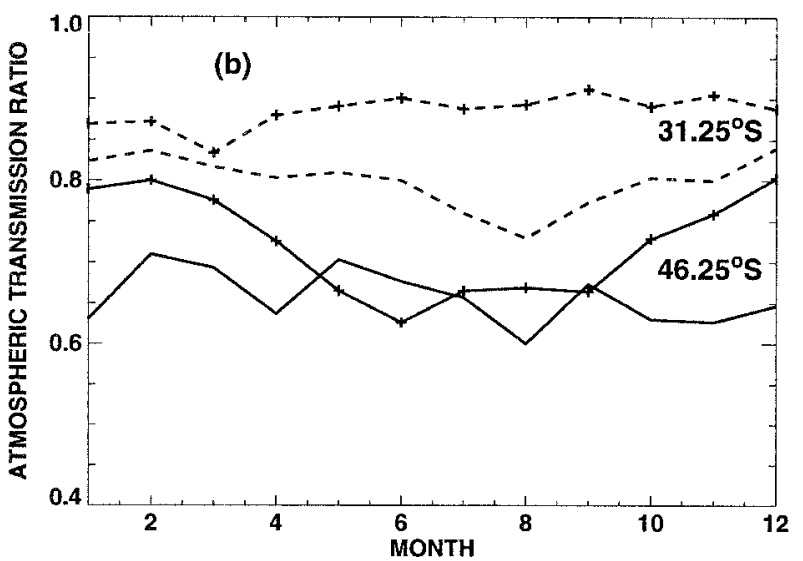

FIG. 5. Annual cycle of (a) monthly mean cloud radiative forcing at the surface and (b) all-sky-clear-sky atmospheric transmission ratio, both averaged over the South America latitudes of $46.25^{\circ}$ (solid) and $31.25^{\circ} \mathrm{S}$ (dashed), and over $3 \mathrm{yr}, 1986-88$. Pluses denote the model results, curves without marks show SRB data.

present the difference between the atmospheric absorption values computed with the code and LBL method for gaseous atmosphere with molecular scattering. The difference reaches $40 \mathrm{~W} \mathrm{~m}^{-2}$ for the midlatitude standard atmosphere (MLS) and solar zenith angle of $30^{\circ}$. This is related largely to the neglect of the absorption due to water vapor continuum, $\mathrm{O}_{2}$, and $\mathrm{CO}_{2}$ in the GCM radiation code. The absorption in the water vapor lines is also slightly underestimated by the code due to use of the absorption function of Yamamoto (1962). The cases 50 and 52 demonstrate that incorporation of the aerosol profile Mar-I (WCRP-112 1986) in the line-byline calculations leads to a small increase of the atmospheric absorption. This is mainly associated with the weak absorption properties of the Mar-I aerosol model, which has the midvisible single-scattering albedo $\left(\omega_{550}\right)$ of 0.99 and column optical depth $\left(\tau_{550}\right)$ of 0.078 .

Table 2 shows that atmospheric absorption increases significantly when calculated with the Cont-I aerosol profile $\left(\omega_{550}=0.89, \tau_{550}=0.22\right)$. In these cases precise calculations were performed with the broadband radi- 

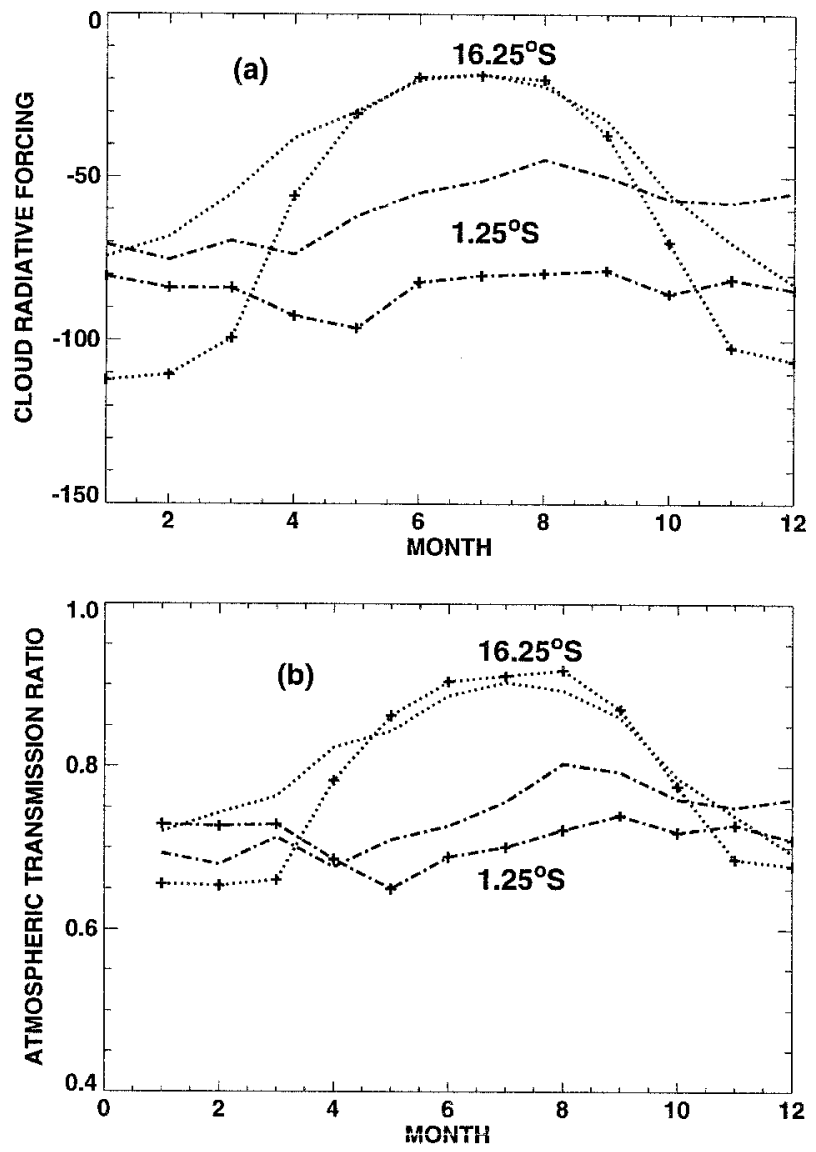

FIG. 6. As in Fig. 5 but for the latitudes of $16.25^{\circ}$ (dotted) and $1.25^{\circ} \mathrm{S}$ (dashed-dotted).

ative transfer algorithm BRTC.01 (Tarasova et al. 1999; Tarasova and Eck 2001) adjusted to the line-by-line method of Fomin and Gershanov (1996) with an accuracy of $1 \%-3 \%$. The difference between the incident fluxes, computed with the model radiation code and with the BRTC.01 algorithm, increases up to $+85.9 \mathrm{~W} \mathrm{~m}^{-2}$ for the MLS atmosphere and solar zenith angle of $30^{\circ}$. The underestimation of the atmospheric absorption by the code reaches $-71.5 \mathrm{~W} \mathrm{~m}^{-2}$. Note that the difference of the daily average values should be three or four times smaller.

\section{Ground-based measurements of all-sky-clear- sky atmospheric transmission ratio in Amazonia}

Solar radiation measurements at the earth's surface provide additional information for validation of both model-simulated and satellite-derived surface solar radiative fluxes. In order to estimate the radiation effect of clouds, the monthly mean all-sky-clear-sky ATR has been determined from the radiation measurements taken in 1993 at three observational sites in Amazonia (Tarasova et al. 2000). The coordinates of the sites are $10^{\circ} 45^{\prime} \mathrm{S}, 62^{\circ} 22^{\prime} \mathrm{W}$, Fazenda Nossa Senhora Aparecida
TABLE 1 . The absolute $(\Delta)$ and relative $(\delta)$ bias between the surface solar radiative fluxes $F_{i, s}$ and atmospheric absorption values $A$, computed with the CPTEC-COLA AGCM shortwave radiation code and LBL method; $A_{s}$, surface albedo; MLS, midlatitude summer atmosphere; TRA, tropical atmosphere; SZA, solar zenith angle.

\begin{tabular}{cccccccc}
\hline \hline Case & ATM & SZA & $A_{s}$ & $\begin{array}{c}\Delta F_{i, s} \\
\left(\mathrm{~W} \mathrm{~m}^{-2}\right)\end{array}$ & $\begin{array}{c}\delta F_{i, s} \\
(\%)\end{array}$ & $\begin{array}{c}\Delta A \\
\left(\mathrm{~W} \mathrm{~m}^{-2}\right)\end{array}$ & $\begin{array}{c}\delta A \\
(\%)\end{array}$ \\
\hline \multicolumn{7}{c}{ Gaseous absorption + molecular scattering } \\
31 & MLS & $30^{\circ}$ & 0.2 & +40.1 & +4.3 & -40.6 & -17.3 \\
33 & MLS & $75^{\circ}$ & 0.2 & +18.6 & +8.3 & -14.6 & -15.1 \\
35 & TRA & $30^{\circ}$ & 0.2 & +42.3 & +4.7 & -43.2 & -17.2 \\
37 & TRA & $75^{\circ}$ & 0.2 & +20.0 & +9.1 & -16.0 & -15.7 \\
Gaseous absorption & + molecular scattering + aerosols & (Mar-I $)$ \\
50 & MLS & $30^{\circ}$ & 0.2 & +48.2 & +5.3 & -46.1 & -19.2 \\
52 & MLS & $75^{\circ}$ & 0.2 & +31.1 & +14.7 & -17.9 & -17.8 \\
\hline \multicolumn{7}{c}{}
\end{tabular}

(NS) located near Ji-Paraná; $5^{\circ} 10^{\prime} \mathrm{S}, 48^{\circ} 45^{\prime} \mathrm{W}$, Fazenda Boa Sorte (BS) located near Marabá; and $2^{\circ} 19^{\prime} \mathrm{S}$, $60^{\circ} 19^{\prime} \mathrm{W}$, Fazenda Dimona (FD) located near Manaus. The all-sky fluxes were measured at the sites by pyranometers. The clear-sky fluxes were computed with the broadband radiative transfer algorithm (Tarasova et al. 1999), which used as inputs aerosol optical depth and precipitable water derived from sun photometer measurements (Holben et al. 1996). The comparison between the measured and calculated clear-sky fluxes was performed for six periods of several hours when the midvisible aerosol optical depth varied from 0.34 to 1.94 and precipitable water changed from 1.9 to 4.3 . The results of the comparison show that the computed fluxes are generally larger by 3\%-9\%. The sensitivity of the flux difference to the aerosol properties used in the calculations is discussed in Tarasova and Eck (2001).

Figure 7 presents the annual cycles of surface-derived ATR for 1993 as compared with the SRB data and model results obtained for the period 1986-88. The interannual variability of monthly mean all-sky surface solar radiative flux at the Amazonian sites in the period 199295 is less than 15\% (Tarasova et al. 2000). The SRB datasets demonstrate the same magnitude of surface flux interannual variability for the period 1986-88. The impact of the El Niño events of 1986-87 and 1991-92 on the surface fluxes is not noticeable in either dataset. Therefore, with the accuracy of $15 \%$ we can compare annual cycles of ATR obtained at the same site in dif-

TABLE 2 . The absolute $(\Delta)$ and relative $(\delta)$ bias between the surface solar radiative fluxes $F_{i, s}$ and atmospheric absorption values $A$, computed with the CPTEC-COLA AGCM shortwave radiation code and BRTC.01 algorithm (accounted for the aerosol model Cont-I); $A_{s}$, surface albedo; MLS, midlatitude summer atmosphere; TRA, tropical atmosphere; SZA, solar zenith angle.

\begin{tabular}{lcccccc}
\hline \hline ATM & SZA & $A_{s}$ & $\begin{array}{c}\Delta F_{i, s} \\
\left(\mathrm{~W} \mathrm{~m}^{-2}\right)\end{array}$ & $\begin{array}{l}\delta F_{i, s} \\
(\%)\end{array}$ & $\begin{array}{c}\Delta A \\
\left(\mathrm{~W} \mathrm{~m}^{-2}\right)\end{array}$ & $\begin{array}{c}\delta A \\
(\%)\end{array}$ \\
\hline MLS & $30^{\circ}$ & 0.2 & +85.9 & +9.8 & -71.5 & -26.9 \\
MLS & $75^{\circ}$ & 0.2 & +53.9 & +28.5 & -29.1 & -26.1 \\
TRA & $30^{\circ}$ & 0.2 & +86.7 & +10.0 & -72.2 & -25.8 \\
TRA & $75^{\circ}$ & 0.2 & +54.2 & +29.3 & -29.3 & -25.5 \\
\hline
\end{tabular}



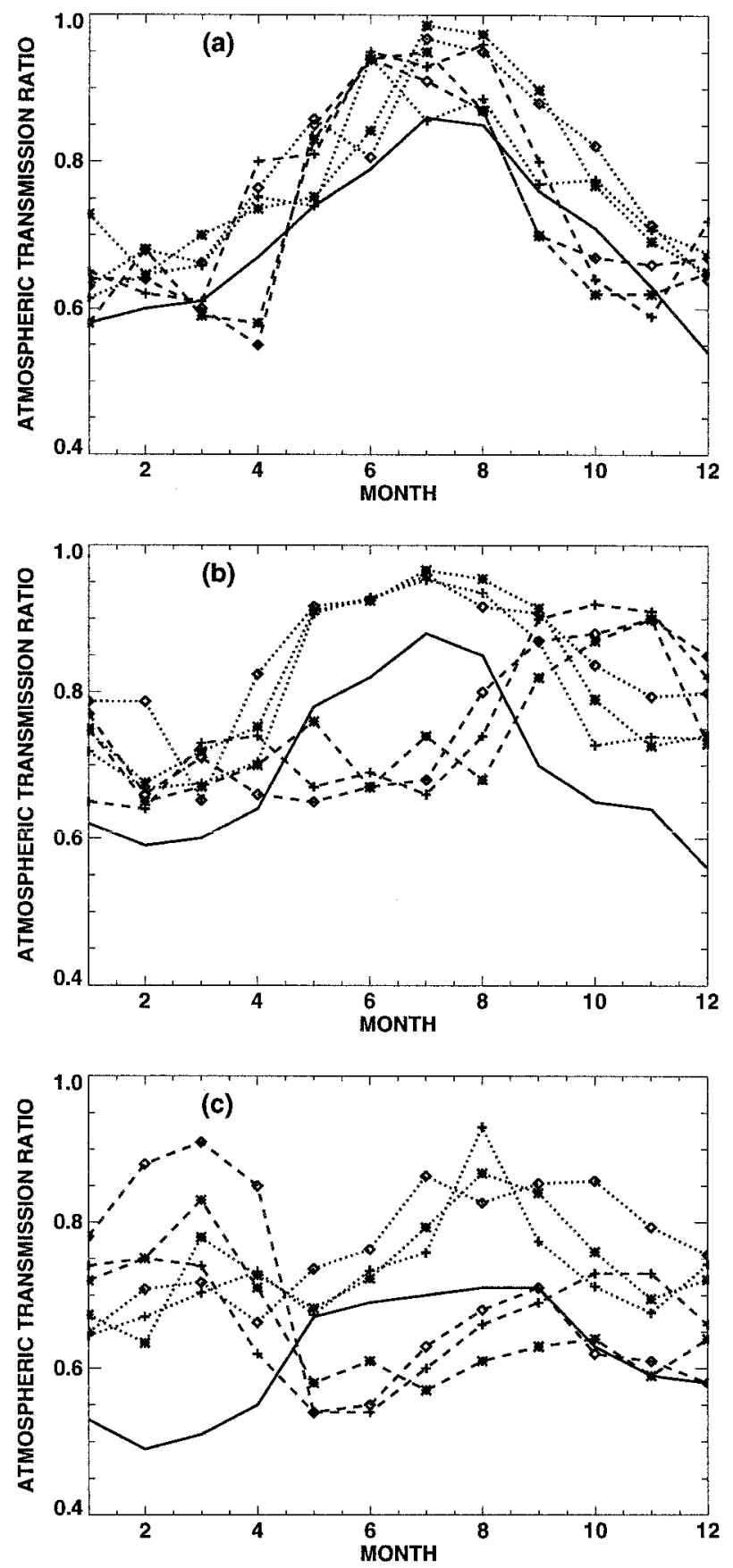

FIG. 7. Comparison between the annual cycles of all-sky-clear-sky atmospheric transmission ratio, obtained from the radiation measurements at the (a) NS, (b) BS, and (c) FD sites in Amazonia in 1993 (solid) as well as provided by the SRB database (dotted) and simulated by the CPTEC-COLA AGCM (dashed) for 1986 (pluses), 1987 (diamonds), and 1988 (asterisks).

ferent years. One can see in Fig. 7 that both satellite and surface-derived datasets demonstrate the same seasonal variations of ATR. The magnitude of ATR at the NS and BS sites changes from about $0.6-0.8$ in the wetseason months to about $0.85-0.98$ in the dry-season period. Nevertheless, the satellite-derived ATR values for the period 1986-88 are systematically larger than surface data obtained in 1993. At the BS and FD sites this cannot be explained by the ATR interannual variability.

One possible explanation of the discrepancy is underestimation of overcast cloud optical depths from satellite measurements (Barker et al. 1998), particularly at the FD site characterized by denser cloudiness throughout a year. Another conceivable reason for the bias is that the point ground-based measurements are not totally representative for the satellite cell of $280 \mathrm{~km}$. We assume that the effect is not strong because the sites are located far from the coastline and mountains and the surrounding areas are covered by pasture grass and forest with closely matched albedo values of 0.17 and 0.14 , respectively. The use of the Cont-I aerosol model in the SRB radiation algorithm cannot cause the systematic bias between the SRB and surface datasets because the optical parameters of the Cont-I model are similar to those of the "smoke" model used for the surface derivation (Tarasova et al. 1999). The bias can increase in August and September only, when the surface method accounts for the elevation of smoke aerosol optical depth.

Figure 7 also shows that the GCM simulates fairly well the seasonal variations of atmospheric transmission ratio at the NS site. At two other sites the model-simulated atmospheric transmission ratio is too small in the dry-season months and too large in some months of the wet season, which is consistent with the precipitation deficiency simulated by the model over large parts of Amazonia in austral summer (Cavalcanti et al. 2001). Near the equator the differences may also be related to the model errors of the simulated ITCZ, which can influence convection over northern Amazonia. Although the model simulates the seasonal displacement of the ITCZ, the intensity is not well represented.

\section{Results and conclusions}

The surface solar radiative fluxes simulated by the CPTEC-COLA GCM over South America for the period 1986-88 were compared with the fluxes provided by the SRB datasets. Zonally averaged fluxes, modelsimulated and satellite-derived, demonstrate similar variations with latitude. Nevertheless, the simulated fluxes are systematically larger in both all-sky and clear-sky conditions. The average difference of all-sky (clear-sky) fluxes is 43 (50) $\mathrm{W} \mathrm{m}^{-2}$ in January and 21 (29) $\mathrm{W} \mathrm{m}^{-2}$ in July. The bias in the clear-sky fluxes is explained in part by the lack of aerosol effects in the shortwave radiation code of the model. The bias in all-sky fluxes includes deficiency in simulation of clouds.

The impact of clouds on the incident radiative fluxes was estimated by calculating cloud radiative forcing and all-sky-clear-sky atmospheric transmission ratio. The ATR quantifies the direct radiation effect of clouds, pro- 
viding that the clear-sky fluxes are accurate, and serves as a measure of both cloud amount and cloud optical depth, which are parameters less accurately measured from the surface. The results show that the model overestimates the SRB surface cloud radiative forcing over the tropical region of South America and underestimates it over the extratropical region in both January and July. This forcing considers all type of clouds, convective and those not related to precipitation. The quantitative bias can reach $40 \mathrm{~W} \mathrm{~m}^{-2}$ when averaged over latitudinal zones.

There are similar variations with latitude of the annual cycle of monthly mean cloud radiative forcing obtained with the use of the two datasets, model simulated and SRB. The annual cycle is weak near the equator and strong at the tropical latitudes because of the different amounts of clouds in the dry and wet seasons. At the extratropical latitudes, the profound annual cycle is mainly associated with the strong seasonal variations of the extraterrestrial solar flux. The atmospheric transmission ratio and hence cloud amount changes slightly during a year. The comparison among model-simulated, satellite-derived, and surface-derived estimates of allsky-clear-sky atmospheric transmission ratio obtained at the three observational sites in Amazonia shows that there is good agreement at the southern site and large discrepancies at two other sites located closer to the equator.

These results were obtained on the basis of 3-yr datasets. Further development of larger datasets (including ground-based measurements) could provide more information for an analysis of the causes of biases. The systematic overestimation of the clear-sky incident flux by the model can be diminished by incorporating the new radiative transfer algorithm. In order to propose methods for improving of large all-sky flux biases obtained for some regions of South America, more detailed comparisons with observational data are needed.

Acknowledgments. T. A. Tarasova was supported by a grant from the Brazilian scientific foundation, Conselho Nacional de Desenvolvimento Cientifico e Tecnologico (CNPq). I. F. A. Cavalcanti is also grateful to CNPq for research funding. We thank three anonymous reviewers for their useful comments.

\section{REFERENCES}

Barker, H. W., T. J. Curtis, E. Leontieva, and K. Stamnes, 1998: Optical depth of overcast cloud across Canada: Estimates based on surface pyranometer and satellite measurements. J. Climate, 11, 2980-2994.

Cavalcanti, I. F. A., and Coauthors, 2001: Climate characteristics in an ensemble simulation using CPTEC/COLA Atmospheric GCM. Instituto Nacional de Pesquisas Espaciais Doc. INPE8150-RPQ/717, $71 \mathrm{pp}$.

Cess, R. D., and Coauthors, 1995: Absorption of solar radiation by clouds: Observations versus models. Science, 267, 496-499.

Clough, S. A., F. X. Kneizys, and R. W. Davies, 1989: Line shape and the water vapor continuum. Atmos. Res., 23, 229-241.
Fomin, B. A., and Y. V. Gershanov, 1996: Tables of the benchmark calculations of atmospheric fluxes for the ICRCCM test cases, Part II: Short-wave results. Preprints, IAE-5990/1, Moscow, Russia, Russian Research Center "Kurchatov Institute," 1-42.

Fouquart, Y., and B. Bonnel, 1991: Intercomparing shortwave radiation codes for climate studies, absorption and water cloud extinction in inhomogeneous atmospheres. J. Geophys. Res., 96, 8955-8968.

Gilgen, H., M. Wild, and A. Ohmura, 1998: Means and trends of shortwave irradiance at the surface estimated from Global Energy Balance Archive Data. J. Climate, 11, 2042-2061.

Holben, B. N., A. Setzer, T. F. Eck, A. Pereira, and I. Slutsker, 1996: Effect of dry-season biomass burning on Amazon Basin aerosol concentrations and optical properties, 1992-1994. J. Geophys. Res., 101, 19 465-19 481.

Hou, Y. T., 1990: Cloud-radiation dynamics interaction. Ph.D. thesis, University of Maryland, $209 \mathrm{pp}$.

Kinter, J. L., III, and Coauthors, 1997: The COLA atmosphere-biosphere general circulation model. Vol. 1: Formulation. Rep. 51, Center for Ocean, Land and Atmosphere Studies, Calverton, Maryland, $46 \mathrm{pp}$.

Kuo, H. L., 1974: Further studies of the parameterization of the in fluence of cumulus convection on large scale flow. J. Atmos. Sci., 31, 1232-1240.

Lacis, A. A., and J. E. Hansen, 1974: A parameterization for the absorption of solar radiation in the earth's atmosphere. J. Atmos. Sci., 31, 118-133.

Laszlo, I., and R. Pinker, 2001: Comparison of broadband radiative transfer calculations with surface flux measurements from CAGEX version 2.2 data. IRS'2000: Current Problems in Atmospheric Radiation, W. L. Smith and Y. M. Timofeyev, Eds., A. Deepak, 540-544.

Li, Z., H. G. Leighton, K. Masuda, and T. Takashima, 1993: Estimation of SW flux absorbed at the surface from TOA reflected flux. J. Climate, 6, 317-330.

Pinker, R., and I. Lazlo, 1992: Modeling surface solar irradiance for satellite applications on a global scale. J. Appl. Meteor., 31, 194211.

Ramanathan, V., 1987: The role of Earth Radiation Budget studies in climate and general circulation research. J. Geophys. Res., 92, 4075-4095.

Reynolds, R. W., and T. M. Smith, 1994: Improved global sea surface temperature analyses using optimum interpolation. J. Climate, 7, 929-948.

Rossow, W. B., L. C. Garder, P.-J. Lu, and A. Walker, 1991: International Satellite Cloud Climatology Project (ISCCP) documentation of cloud data. WMO Tech. Doc. WMO/TD-No. 266, 153 pp.

Rothman, L. S., and Coauthors, 1998: The HITRAN molecular database and HAWKS, 1996 edition. J. Quant. Spectrosc. Rad. Transfer, 60, 665-710.

Sato, N. P., J. Sellers, D. A. Randall, E. K. Schneider, J. Shukla, J. L. Kinter III, Y. T. Hou, and E. Albertazzi, 1989: Effects of implementing the Simple Biosphere Model in a general circulation model. J. Atmos. Sci., 46, 2757-2782.

Slingo, J. M., 1987: The development and verification of a cloud prediction scheme for the ECMWF model. Quart. J. Roy. Meteor. Soc., 113, 899-927.

Suttles, J. T., B. A. Wielicki, and S. Vemury, 1992: Top-of-atmosphere radiative fluxes: Validation of ERBE scanner inversion algorithm using Nimbus-7 ERB data. J. Appl. Meteor., 31, 784-796.

Tarasova, T. A., and I. F. A. Cavalcanti, 2000: Cloud radiative forcing over South America: Comparison of CPTEC/COLA AGCM output with SRB data. Preprints, Sixth Int. Conf. on Southern Hemisphere Meteorology and Oceanography, Santiago, Chile, Amer. Meteor. Soc., 256-257.

, and T. F. Eck, 2001: Improvements in the broadband radiative transfer code aimed to achieve better agreement between modeled and measured solar irradiances on the ground. IRS'2000: 
Current Problems in Atmospheric Radiation, W. L. Smith and Y. M. Timofeyev, Eds., A. Deepak, 1073-1077.

, C. A. Nobre, B. N. Holben, T. F. Eck, and A. Setzer, 1999: Assessment of the smoke aerosol impact on the surface solar irradiance measured in the Rondonia region of Brazil during SCAR-B. J. Geophys. Res., 104, 19 161-19 170.

, — - T. F. Eck, and B. N. Holben, 2000: Modeling of gaseous, aerosol, and cloudiness effects on surface solar irradiance measured in Brazil's Amazonia 1992-1995. J. Geophys. Res., 105, 26 961-26969.

Whitlock, C. H., T. P. Charlock, W. F. Staylor, R. T. Pinker, I. Laszlo, R. C. DiPasquale, and N. A. Ritchey, 1993: WCRP Surface Radiation Budget Shortwave Data Product Description-Version 1.1. NASA Tech. Memo. 107747, National Technical Information Service, Springfield, Virginia, $28 \mathrm{pp}$.

Wild, M., 1999: Discrepancies between model-calculated and observed shortwave atmospheric absorption in areas with high aerosol loadings. J. Geophys. Res., 104, 27 361-27 371.
— mosphere in the problem of underestimated absorption of solar radiation in GCM atmosphere. Phys. Chem. Earth, 24B, 261268.

_ _ _ - H. Gilden, and E. Roeckner, 1995: Regional climate simulation with a high resolution GCM: Surface radiative fluxes. Climate Dyn., 11, 469-486.

World Meteorological Organization, 1986: World Climate Research Programme: A preliminary cloudless standard atmosphere for radiation computation. WMO Tech. Doc. WCP-112, WMO/TD 24, $53 \mathrm{pp}$.

Xue, Y., P. J. Sellers, J. L. Kinter III, and J. Shukla, 1991: A simplified biophere model for global climate studies. J. Climate, 4, 345364

Yamamoto, G., 1962: Direct absorption of solar radiation by atmospheric water vapor, carbon dioxide and molecular oxygen. $J$. Atmos. Sci., 19, 182-188. 